\title{
ANTIFUNGAL INFLUENCE OF A MELANIN PRODUCER PSEUDONADSONIELLA BRUNNEA CULTURE FLUID ON GIBBERELLA FUJIKUROI (ANAMORPH: FUSARIUM VERTICILLIOIDES)
}

\author{
T. Kondratiuk* ${ }^{*}$ T. Beregova and L. Ostapchenko \\ Educational and Scientific Centre 'Institute of Biology and Medicine' \\ Taras Shevchenko National University of Kiev, Volodymyrska str. 64/13, 01601 Kyiv, Ukraine; \\ ${ }^{*}$ E-mail: takbiofak@ukr.net
}

(Received 1 December, 2016; Accepted 20 January, 2017)

\begin{abstract}
The influence of culture fluid of a yeast-like fungus, melanin producer Pseudonadsoniella brunnea (Meripilaceae, Agaricomycotina) on pathogenic fungi of the genus Gibberella (anamorph of Gibberella fujikuroi, i.e.: Fusarium verticillioides) (Nectriaceae, Ascomycotina) is studied by using the agar diffusion method. The stable fungicidal effect of Ps. brunnea culture fluid on pathogenic fungi investigated found to be present. The diameter of the zones of absence of growth of test cultures of pathogenic fungi, those testified the fungicidal impact of Ps. brunnea culture fluid, found to be similar to the action of biocides belonging to the class of quaternary ammonium compounds (benzalkonium chloride).
\end{abstract}

Key words: antifungal activity, black yeast-like fungi, pathogenic Fusarium

\section{INTRODUCTION}

The development of biotechnology, which is based on the potential of microorganisms in obtaining biologically active substances (BAS), which can be widely used in various fields of human activity, is one of the main areas of modern world science.

The fungi of the genus Fusarium Link are the most common pathogens and harmful fungal diseases of crops. Today, many species of the genus Fusarium considered to be the members of the genus Gibberella Sacc. after the teleomorphic (sexual) stage. So Fusarium verticillioides (Sacc.) Nirenberg (synonym Fusarium moniliforme J. Sheld.), is now considered to be synonym to Gibberella fujikuroi (Sawada) Wollenw. complex. Fungi of the genus Gibberella are often pathogenic on corn (corn cobs disease) and other crops (rice, sugar reed, soybeans, etc.) in the world, especially in areas with high humidity and in years 
with high rainfall (rain) (to more than $60 \%$ of corn harvest may be damaged by Gibberella in these areas) (Adamenko 2015, Gamboa-Gaitán 2013, Görtz et al. 2008, Hsuan et al. 2011, Leslie and Summerell 2013, Saremi et al. 2008). For most Fusarium species, the sexual cycle is not predominated in the field (Trail 2013). Fungi of the genus Gibberella (anamorphs of the genus Fusarium) can produce mycotoxins (the fumonisins), which cause a carcinogenic effect on animals and humans. The presence of this toxin in plants is subjected to strict control (Görtz et al. 2008, Leslie and Summerell 2013, Nishiuchi 2013).

The microorganisms of different taxonomic and physiological groups and their metabolic products and the drugs created on the base on these biological substances are now widely used in many countries to protect crops from pathogenic fungi. This can significantly reduce the negative impact on the environment, including agrocoenosis, which is inflicted by chemicals (pesticides). The use of biological agents against pathogenic fungi not only provides plant protection from diseases, but may stimulate their growth and development, enhance seed germination, increase productivity. The most common method of biocontrol of pathogenic fungi is search of antagonist microorganisms. The methods of biocontrol of pathogenic fungi are environmentally safe, cost-effective and do not disturb ecological balance (Alabouvette et al. 2006, Borrero et al. 2012, Castano et al. 2013, Isaac and Abu-Tahon 2014, Maslichenko et al. 2011, Tkalenko et al. 2012, Yang et al. 2011, Zaimenko et al. 2015). Thus, the research aimed at finding BAS microorganisms to create on their basis of biological agents that protect plants from pathogens, is relevant direction.

Special attention of researchers is deserved to microorganisms, producers of BAS habitats which are associated with extreme conditions. The stringent physical and chemical factors causing significant adaptive changes in microorganisms, accompanied by increased synthesis of a number of metabolites (potential BAS). For example, the metabolites of such Antarctic microscopic fungi found to be potent sources of antimicrobial and antifungal activity (Svahn et al. 2015).

Microscopic fungi and bacteria with distinct physiological and biochemical characteristics, pointing the adaptation to adverse environmental conditions (synthesis and accumulation of lipids, expression of antagonistic properties in relation to other microorganisms) were found during a preliminary study of samples of moss, soil, lichen obtained from Ukrainian Antarctic expeditions (Kondratiuk et al. 2015). The Antarctic black yeast-like fungus Pseudonadsoniella brunnea T. O. Kondratyuk et S. Y. Kondr. (Meripilaceae, Agaricomycotina) (Kondratyuk et al. 2015) synthesises and excretes into a culture fluid dark pigment melanin, which is inherent in a wide range of biological effects, i.e.: antioxidant, wound healing, antibacterial, and fungistatic actions (Taburets et al. 2016). 
The fungicidal effect of melanin producer Pseudonadsoniella brunnea culture fluid on test cultures of pathogenic fungi Fusarium oxysporum Scherht. emend. Snyder et Hansen for the first time found in our previous studies (Kondratiuk et al. 2016).

The purpose of this study was to find out the nature of influence of the culture fluid of Pseudonadsoniella brunnea on pathogenic fungi Gibberella fujikuroi.

\section{MATERIALS AND METHODS}

The pure cultures of pathogenic fungus Gibberella fujikuroi (anamorph: Fusarium verticillioides) from the collection of microscopic fungi of Taras Shevchenko National University of Kiev (international acronym of collection: FCKU) - Gibberella fujikuroi 234 FCKU, G. fujikuroi 333 FCKU, G. fujikuroi 338 FCKU, and G. fujikuroi 434 FCKU, as well as the culture fluid of Antarctic black yeast-like fungus, melanin producers Pseudonadsoniella brunnea 470 FCKU (Kondratyuk et al. 2015b) were used for this study. The cultivation of Pseudonadsoniella brunnea was performed on a standard liquid culture medium, the Maltese-extract broth (MEB, HiMedia Laboratories, India).

The standard potato-dextrose agar (PDA) culture medium was used for cultivation of Gibberella fujikuroi. Performance of Pseudonadsoniella brunnea culture fluid on test culture of fungus Gibberella fujikuroi was compared with the effect of the biocide known class of quaternary ammonium compounds benzalkonium chloride (trade name Katamin $\mathrm{AB}$ ) at a concentration of $3 \%$ for the active substance.

The method of diffusion in agar was used to study the antifungal action of the compounds tested. The suspension of G. fujikuroi with density of $10^{6}$ conidia/ml was used. Term cultivation was 30 days at a temperature of $28^{\circ} \mathrm{C}$.

The impact of Pseudonadsoniella brunnea culture fluid and benzalkonium chloride on Gibberella fujikuroi was determined by the diameter of the zones with absence of growth of test cultures of fungi that formed around the hole, where the test compound was added in culture. Cultures without additions of Pseudonadsoniella brunnea culture fluid and biocide mentioned were served as control cultures.

Trinocular microscope Primo Star of Carl Zeiss and related morphometric computer program AxioVision 4.8 (Carl Zeiss) were used for study of morphological features of studied fungi. Calculation of arithmetic mean and standard deviation using Statistica 12 was used for analysing morphometric parameters of Gibberella fujikuroi, and the diameter of the zones of growth absence. 


\section{RESULTS AND DISCUSSION}

Within our study the Pseudonadsoniella brunnea culture fluid found to have fungicidal effect on the studied test cultures of pathogenic fungi Gibberella fujikuroi (strains 234 FCKU, 333 FCKU, 338 FCKU and 434 FCKU). The growth of all used strains of G. fujikuroi found to be characterised mainly by individual colonies of different diameters under influence of both Pseudonadsoniella brunnea culture fluid and biocide benzalkonium chloride. The colour of the mycelium of G. fujikuroi cultures found to be also changed, i.e.: mycelium of the strains 234 FCKU and 434 FCKU became bright burgundy, while mycelium of the strains of 333 FCKU and 338 FCKU became white-pink colour under the influence of the compounds unlike being pink with a purple tinge in control cultures of all strains studied (Figs 1-2).

It should be especially emphasised that increased synthesis of pigments by Gibberella fujikuroi strains 234 FCKU and 434 FCKU influenced by Pseudonadsoniella brunnea culture fluid was observed. It is known that under the influence of various factors, including stress, the fungi of the Gibberella fujikuroi complex (anamorphs of the genus Fusarium) can synthesise important biologically active pigments of interest in connection with a wide range of biological activity (antibacterial, antifungal, phytotoxic, insecticidal, and cytotoxic, etc.) (Deshmukh et al. 2015, Pradeep and Pradeep 2013).

It was also established that the diameter of the zones without growth of the Gibberella fujikuroi test cultures, exposed to fungicidal activity of Pseudo-
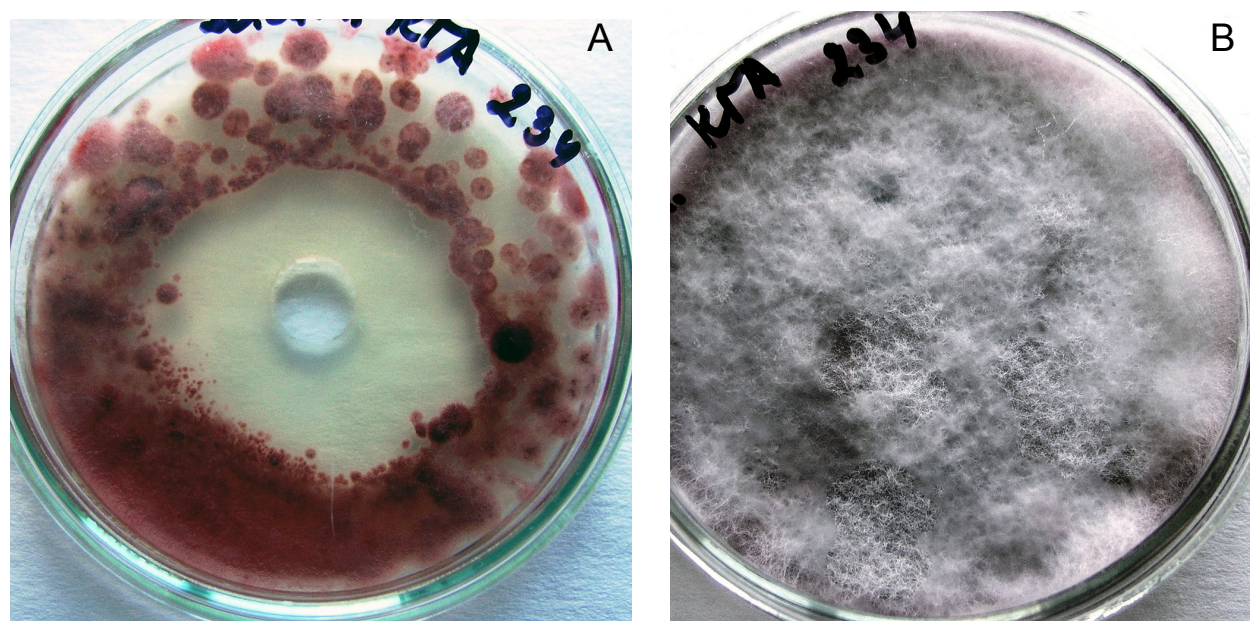

Fig. 1. Effect of Pseudonadsoniella brunnea culture fluid on the Gibberella fujikuroi 234 FCKU test culture. $\mathrm{A}=$ the absence of growth zone around the hole, where the Pseudonadsoniella brunnea culture fluid was added; $\mathrm{B}=$ control culture 

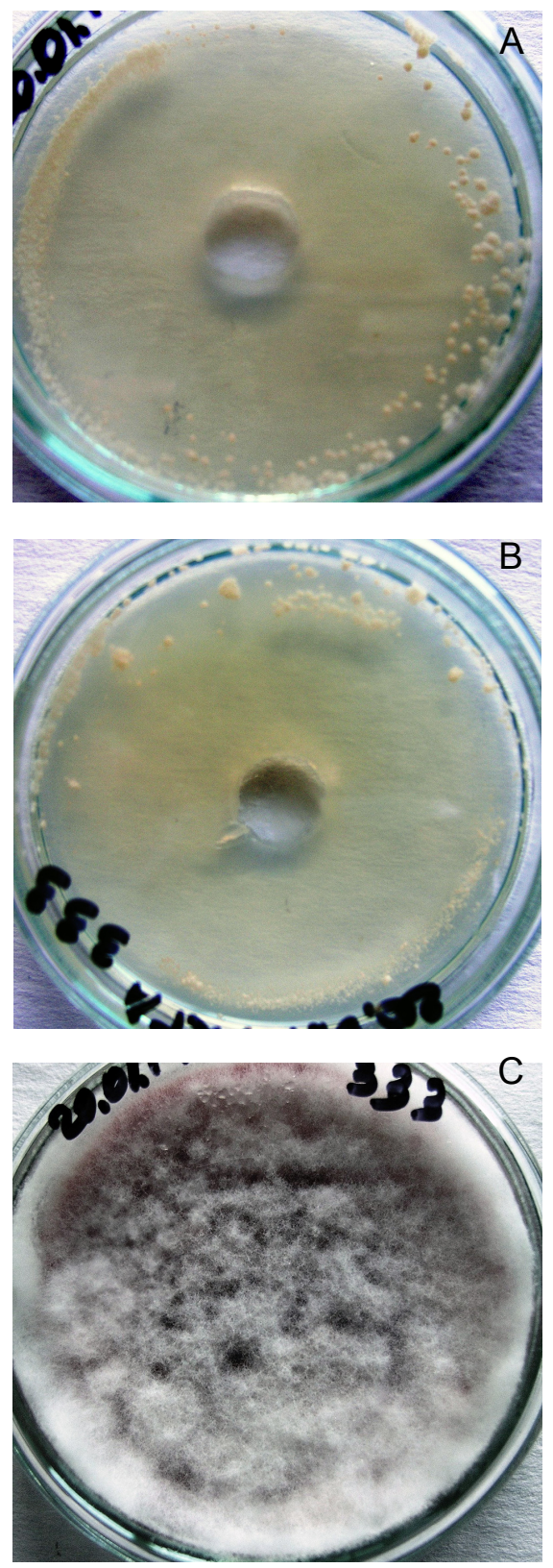

Fig. 2. Zones of absence of Gibberella fujikuroi 333 FCKU growth under influence of Pseudonadsoniella brunnea culture fluid (A) and benzalkonium chloride (B). $\mathrm{C}=$ control culture nadsoniella brunnea culture fluid, is similar to the diameter of the sterile zones formed under the influence of biocide benzalkonium chloride (Fig. 2, Table 1).

Different strains of Gibberella fujikuroi test cultures found to show different sensitivity to the effects of studied compounds, as evidenced by data on the diameter of the zones of growth delay (Table 1) similarly to our previous study of Fusarium oxysporum resistance to impact studied compounds (Kondratiuk et al. 2016). Our data on the diameter of the zones of stunted growth of Gibberella fujikuroi test cultures were compared also with an antagonistic effect of fungi of the genus Trichoderma on pathogenic fungi of the genera Gibberella and Fusarium after data of other authors (Tkalenko et al. 2012). From this comparison the effect of Pseudonadsoniella brunnea culture fluid on pathogenic fungi Gibberella fujikuroi (anamorph Fusarium verticillioides) can be assessed as highly active.

Thus, fungicidal effect of melanin producer, black yeast Pseudonadsoniella brunnea culture fluid on test cultures of pathogenic fungi Gibberella fujikuroi (anamorph Fusarium verticillioides) is for the first time established within this study.

This direction of research is rather promising and needs to be continued in determining the chemical composition of the Pseudonadsoniella brunnea culture fluid and enlargement of number of test cultures of microorganisms. The usage of metabolic substances of microorganisms, which can inhibit the growth of other microorganisms (including pathogenic microscopic fungi and bacteria) as biological methods of pest manage- 
Table 1

Antifungal effect of Pseudonadsoniella brunnea culture fluid and benzalkonium chloride on the Gibberella fujikuroi test cultures

\begin{tabular}{lcccc}
\hline Compounds tested & \multicolumn{4}{c}{ The diameter of the zones without growth } \\
& of fulgal test cultures, mm \\
\cline { 2 - 5 } & 234 FCKU & 333 FCKU & 338 FCKU & 434 FCKU \\
\hline $\begin{array}{l}\text { Pseudonadsoniella brun- } \\
\text { nea culture fluid }\end{array}$ & $47.5 \pm 0.1$ & $69.2 \pm 0.12$ & $48.9 \pm 0.11$ & $51.3 \pm 0.11$ \\
Benzalkonium chloride & $50.8 \pm 0.09$ & $73.3 \pm 0.1$ & $55.2 \pm 0.08$ & $59.7 \pm 0.09$ \\
Control & $0^{*}$ & $0^{*}$ & $0^{*}$ & $0^{*}$ \\
\hline
\end{tabular}

* $=$ sterile zones in control cultures entirely absent

ment of agricultural production will result in decreasing a negative impact on the environment that is caused by biocidal chemicals.

Acknowledgements - We are thankful to Mgr Anna Kalinichenko (Kyiv, Ukraine) for technical assistance during carrying out this study, and Dr László Lőkös (Budapest, Hungary) for valuable comments on the manuscript and improvements of English.

\section{REFERENCES}

Adamenko, O. P. (2015): Vydovyj sklad zbudnykov fuzariozu soyi ta yih patogennistj. Visnyk Centru naukovogo zabezpechennya APV Kharkiv oblastj 18: 5-11. [in Ukrainian]

Alabouvette, C., Olivain, C. and Steinberg, C. (2006): Biological control of plant diseases: the European situation. - European J. Plant Pathol. 114(3): 329-341. https://doi. org/10.1007/s10658-005-0233-0

Borrero, C., Trillas, M., Delgado, A. and Aviles, M. (2012): Effect of ammonium/nitrate ratio in nutrient solution on control of Fusarium wilt of tomato by Trichoderma asperellum T34. - Plant Pathol. 61(1): 132-139. https://doi.org/10.1111/j.1365-3059.2011.02490.x

Castano, R., Borrero, C., Trillas, M. I. and Aviles, M. (2013): Selection of biological control agents against tomato Fusarium wilt and evaluation in greenhouse conditions of two selected agents in three growing media. - Biocontrol 58(1): 105-116. https://doi. org/10.1007/s10526-012-9465-z

Deshmukh, S. K., Verekar, S. A. and Bhave, S. V. (2015): Endophytic fungi: a reservoir of antibacterials. - Front. Microbiol. 5: 715-724. https://doi.org/10.3389/fmicb.2014.00715

Gamboa-Gaitán, M. (2013): Colombian Vanilla and its microbiota, I. First report of Fusarium taxa from both wild and cultivated species. - Acta Bot. Hung. 55(3-4). https://doi. org/10.1556/ABot.55.2013.3-4.6

Görtz, A., Oerke, E.-C., Steiner U., Waalwijk, C., de Vries P. M. and Dehne H.-W. (2008): Biodiversity of Fusarium species causing ear rot of maize in Germany. - Cereal Res. Comm. 36 (Suppl. 6): 617-622. https://doi.org/10.1556/CRC.36.2008.Suppl.B.51 
Hsuan, H. M., Salleh, B. and Zakaria, L. (2011): Molecular identification of Fusarium species in Gibberella fujikuroi species complex from rice, sugarcane and maize from Peninsular Malaysia. - Int. J. Mol. Sci. 12(10): 6722-6732. https://doi.org/10.3390/ijms12106722.

Isaac, G. and Abu-Tahon, M. (2014): In vitro antifugal activity of medicinal plant extract against Fusarium oxysporum f. sp. - Acta Biol. Hung. 65(1): 107-118. https://doi. org/10.1556/ABiol.65.2014.1.10

Kondratiuk, T., Beregova, T. and Ostapchenko, L. (2016): Antifungal influence of culture fluid of melanin producer Pseudonadsoniella brunnea. - ScienceRise: Biological Science 3(3): 74-78. [in Ukrainian]

Kondratiuk, T. O., Morgaienko, O. O., Beregova, T. V. and Ostapchenko, L. I. (2015): Peculiarities of Antarctic microorganisms and perspectives of their usage in biotechnology and medicine. - Abstracts, VII International Antarctic Conference "Antarctic research: new horizons and priorities", pp. 57-59.

Kondratyuk, T. O., Kondratyuk, S. Y., Morgaienko, O. O., Khimich, M. V., Beregova, T. V. and Ostapchenko, L. I. (2015): Pseudonadsoniella brunnea (Meripilaceae, Agaricomycotina), a new brown yeast-like fungus producing melanin from the Antarctic; with notes on nomenclature and type confusion of Nadsoniella nigra Issatsch. - Acta Bot. Hung. 57(3-4): 291-320. https://doi.org/10.1556/034.57.2015.3-4.5

Leslie, J. F. and Summerell, B. A. (2013): An overview of Fusarium. - In: Brown, D. W. and Proctor, R. H. (eds): Fusarium: genomics, molecular and cellular biology, pp. 1-10.

Maslichenko, L. V., Kurilova, D. A. and Manohin, V. L. (2011): Vliyanie mikrobiopreparatov na osnove perspektivnih schtamov antagonistov vozbuditelej fusariosa na kulturu soi. - Maslichnyey kuljtury 2: 145-148. [in Russian]

Nishiuchi, T. (2013): Plant responses to Fusarium metabolites. - In: Brown, D. W. and Proctor, R. H. (eds): Fusarium: genomics, molecular and cellular biology, pp. 165-178.

Pradeep, F. S. and Pradeep, B. V. (2013): Optimization of pigment and biomass production from Fusarium moniliforme under submerged fermentation conditions. - Int. J. Pharm. Pharm. Sci. 5 (Suppl. 3): 526-535.

Saremi, H., Ammarellou, A., Marefat, A. and Okhovvat, S. M. (2008): Binam a rice cultivar, resistant for root rot disease on rice caused by Fusarium moniliforme in Northwest, Iran. - Int. J. Bot. 4: 383-389. https://doi.org/10.3923/ijb.2008.383.389

Svahn, S. K., Chryssanthou, E., Olsen, B., Bohlin, L. and Göransson, U. (2015): Penicillium nalgiovense Laxa isolated from Antarctica is a new source of the antifungal metabolite amphotericin B. - Fungal Biol. Biotechnol. 1: 2-11. https://doi.org/10.1186/s40694014-0011-x

Taburets, O. V., Morgaienko, O. O., Kondratiuk, T. O., Beregova, T. V. and Ostapchenko, L. I. (2016): The effect of "Melanin-Gel" on the wound healing. - J. Pharm. Chem. Biol. Sci. 7(3): 2031-2038.

Tkalenko, G. M., Borsih, O. I. and Sergienko, V. G. (2012): Optimisaciya zahistu ovohevih kultur v Lisosstepu Ukraine. - Karantyn $i$ zakhyst roslyn 3: 9-14. [in Ukrainian]

Trail, F. (2013): Sex and fruiting in Fusarium. - In: Brown, D. W. and Proctor, R. H. (eds): Fusarium: genomics, molecular and cellular biology. Caister Academic Press, Norfolk, pp. 11-30.

Yang, X., Chen, L., Yong, X. and Shen, Q. (2011): Formulations can affect rhizosphere colonization and biocontrol efficiency of Trichoderma harzianum against Fusarium wilt of cucumbers. - Biol. and Fert. Soils 47(3): 239-248. https://doi.org/10.1007/s00374-010-0527-z

Zaimenko, N., Didik, N., Ellanska, N., Pavlyuchenko, N., Yunosheva, A., Zakrasov, O. and Rosicka, N. (2015): Prospects of exometabolites of micromycetae and analcime application for cabbage plant protection from fusariose. - Agroecol. J. 3: 87-92. 